\title{
La megacausa Operativo Independencia en Tucumán "Las inspecciones oculares" en los centros clandestinos de detención (1975-1976)
}

\author{
Francisco Bolsi ${ }^{1}$ \\ ${ }^{1}$ Instituto Superior de Estudios Sociales (ISES-CONICET). Tucumán-Argentina \\ ORCiD: 00oo-0001-9446-8955 \\ Correo electrónico: franciscobolsi@hotmail.com
}

Recibido

agosto de 2019

Aceptado

junio de 2020

doi: $10.34096 /$ cas.i52.6367

\section{Resumen}

Esta investigación aborda los centros clandestinos de detención que se instalaron durante la implementación del Operativo Independencia y la mira que tiene la justicia sobre estos espacios. Por este motivo, en este artículo se analizarán las visitas realizadas por el Tribunal de la megacausa Operativo Independencia a los centros clandestinos de detención de la Escuela Diego de Rojas -también conocida en la jerga de los Organismos de Derechos Humanos como "la Escuelita" - y del ingenio Fronterita -actualmente en funcionamiento- donde se emplazó una base militar que funcionó como centro clandestino de paso. Las fuentes utilizadas para la elaboración de este artículo son el material de video filmado por Gendarmería Nacional, el cuaderno de campo y los autos de procesamiento de la megacausa Operativo Independencia.

The Independence Mega cause in Tucumán. "Eye inspections" at the clandestine detention centers (1975-1976)

\footnotetext{
Abstract

This research examines the Clandestine Detention Centers that were installed during the implementation of Operation Independence and justice's approach to these spaces. For this reason, the article analyzes the visits made by the Operation Independence mega cause court to the Clandestine Detention Center, the Diego de Rojas school - also known in human rights organization's jargon as the "Little school" - and the Fronterita sugar mill - currently in operation - where a military base that functioned as a Clandestine transit center was located. The sources used for the elaboration of this article are the video material filmed by the National Gendarmerie, fieldnotes and the indictment of the Operation Independence mega cause.
}

\section{Palabras clave}

Justicia; Famaillá; Ritual jurídico; Represión; Memorias

\section{Key words}

Justice; Famaillá; Legal ritual; Repression; Memory 
Palavras-chave

Justiça; Famaillá; Ritual jurídico; Repressão; Memória

\section{A mega-causa do Operativo Independência em Tucumán. "As Inspeções oculares" nos Centros Clandestinos de Detenção (1975-1976).}

\section{Resumo}

Esta investigação pesquisa os Centros Clandestinos de Detenção que foram instalados durante a implementação do Operativo Independência e o olhar que a justiça tem sobre esses espaços. Assim, este artigo discutirá as visitas feitas pelo Tribunal da mega causa judicial Operativo Independência, aos centros de detenção clandestinos da escola Diego de Rojas - também conhecida no jargão das agências de direitos humanos como "a escola" - e o engenho Fronterita - atualmente em funcionamento - onde se estabeleceu uma base militar que funcionava como um centro clandestino de passagem. As fontes utilizadas para a elaboração deste artigo são o material de vídeo filmado pela Gendarmeria Nacional, o caderno de campo e as atas de processamento da Mega causa Operativo Independência.

\section{Introducción}

La historia reciente de América Latina se caracterizó en la década de los setenta por sucesivos golpes de Estado que reemplazaron los gobiernos democráticos por cruentas dictaduras militares que resquebrajaron el tejido social, implementaron el terrorismo de Estado e instalaron diversos mecanismos de desaparición de militantes políticos y estudiantes -entre otros actores sociales-con el propósito de disciplinar a la sociedad. Con el retorno de la democracia, los cientistas sociales se interesaron en indagar en ese pasado latinoamericano, en las dinámicas de las dictaduras, la relación del Estado con las políticas neoliberales, la consolidación del movimiento obrero, los sistemas de partidos y la circulación del capital, entre otros temas significativos (Borón, 2003; López, Figueroa y Rajland, 2010; Allier Montaño y Crenzel, 2015).

Un campo fructífero en las investigaciones acerca de la historia reciente lo constituyen los estudios de memoria. Uno de los pioneros fue Maurice Halbwachs (1968), aunque fue recién a partir de los años setenta que este tópico tomó centralidad en las ciencias sociales. En el caso de América Latina y Argentina, la memoria se transformó en un campo en disputa a partir de fines de los años ochenta y principios de los noventa cuando finalizaron la mayoría de las dictaduras que se establecieron desde la década de 1960 en el Cono Sur- a causa de las a las demandas de justicia de los familiares de los desaparecidos (Feld, 2016).

En el caso de Argentina, un elemento significativo en el abordaje y la interpelación de ese pasado fueron las narrativas testimoniales que en la década de los noventa plantearon otra forma de indagar la memoria social y en las que los organismos de derechos humanos (en adelante, DDHH) fueron centrales en la reconstrucción de ese pasado traumático, a fin de romper con la hegemonía de la década menemista, que garantizó la impunidad de los responsables de los delitos de lesa humanidad durante la dictadura (Chama y Sorgentini, 2010). Este nuevo escenario generó diversos debates y puso a la memoria en un lugar central, situación que influenció en los cientistas sociales, quienes no fueron ajenos a las disputas por ese pasado. Por este motivo, la implementación de un programa desarrollado por el Panel Regional de América Latina del Social Science Research Council -cuyo objetivo fue promover la investigación y formación de jóvenes investigadores que indagaran en las memorias de la represión política en 
el Cono Sur- resultó fundamental (Jelin, 2002). A partir de este suceso, la producción historiográfica se incrementó notablemente: en un primer momento, se enfocó en las consecuencias de la dictadura con marcos claramente establecidos (Catela Da Silva, 2001; Ollier, 2005; Carnovale, 2007); luego, la mirada se centró en las dinámicas internas de los regímenes militares y en los momentos previos a los golpes de Estado (Calveiro, 2005; Franco, 2012); como así también en las imágenes y los escenarios que se dieron durante la represión (Jelin y Longoni, 2005); posteriormente se analizaron las memorias de la política en relación con los derechos humanos luego de caídas las dictaduras (Izaguirre, 1998; Jelin, 2005); y una línea significativa se abocó a indagar en los actores sociales que fueron poco visibles en las historias oficiales, pero que tienen relación con los traumas de las víctimas (Kahan, 2004; Feld, 2009; Wikinski, 2016). Asimismo, una línea innovadora se vincula con la memoria del ejército luego de los procesos de memoria, verdad y justicia (Salvi, 2012).

En el caso tucumano, los organismos de DDHH se movilizaron significativamente cuando el exrepresor Antonio Domingo Bussi fue elegido como intendente y, en forma posterior, como gobernador, hecho que interpeló a los cientistas sociales del medio local, quienes iniciaron nuevas líneas de investigación a fin de estudiar la historia reciente de la provincia (Kotler, 2006, 2007, 2008; Pucci, 2009; Nassif, 2011, 2012, 2015; Cortes Navarro, 2015; Vitar, 2015; Mena, 2016, entre otros). Sin embargo, los estudios desde la perspectiva de la memoria son escasos, motivo por el cual este trabajo pretende ser un aporte a este campo de análisis.

De la misma manera, una herramienta fundamental para esta investigación fue la observación, durante 16 meses, de la megacausa Operativo Independencia, por lo que resultó imperativo analizar los abordajes etnográficos realizados en otros juicios de lesa humanidad. Estos aportes abordaron temáticas como el ritual jurídico, el contexto judicial, las disputas por el poder en dicho escenario, el accionar de los organismos de DDHH y la búsqueda de la verdad jurídica para que esta restableciera la "verdad histórica" (Kauffman, 1991; Sarrabayrouse, 1998, 2012; Mira, 2011; González Leegstra, 2012; Schoenle, 2013, 2015; Tello, 2015; Sanjurjo, 2016). Estos trabajos fueron fundamentales como marco teórico referencial a partir del cual orientar la observación del juicio del Operativo, que se realizó en Tucumán desde el 5 de mayo hasta el 15 de septiembre de 2017.

Por este motivo, el propósito de esta investigación fue analizar las inspecciones oculares realizadas en la escuela Diego de Rojas - conocida como la "Escuelita de Famaillá" - y el ingenio Fronterita, la memoria de los "testigos oculares" en torno a estos espacios -teniendo en cuenta que declararon en un contexto judicial luego de 41 años-; qué traumas se reactualizaron en los testigos en la visita a estos dos centros clandestinos de detención (en adelante, CCD); las disputas que esas memorias produjeron entre los actores judiciales Ministerio Público Fiscal y Defensa Pública-; las formas en que el Tribunal observó estos espacios y la interacción con los testigos; de qué manera tuvieron lugar las disputas por el poder entre los actores judiciales por establecer una verdad jurídica y de qué forma esto produce una verdad "histórica". Asimismo, se analizó cómo el ritual jurídico cobra una dimensión diferente debido a que no queda acotado a un espacio físico delimitado como el Tribunal Oral Federal de Tucumán (en adelante, TOF), sino que las inspecciones oculares requirieron de un traslado de los actores judiciales a los diferentes CCD a fin que los testigos relataran las condiciones de su detención en ellos.

Las fuentes consultadas para la elaboración de este trabajo son los autos de procesamiento del juicio del Operativo Independencia (Exp. 401015/04 y 401016/04 del Poder Judicial de la Nación), el trabajo de campo efectuado durante las inspecciones realizadas en el mes de marzo de 2017, las grabaciones de las inspecciones oculares facilitadas por la Secretaría de Derechos Humanos del TOF y las anotaciones realizadas en el cuaderno de campo en el transcurso del juicio entre mayo de 2016 a septiembre de 2017. 
1. En Tucumán, desde el año 2008, se realizaron 11 juicios de lesa humanidad, a partir de los cuales se condenó a 57 individuos pertenecientes al Ejército, Policía Federal y Provincial.

2. TOF, "Los autos de procesamiento del juicio del Operativo Independencia", Exp. 401015/04 y 401016/04, Poder Judicial de la

\section{La megacausa Operativo Independencia}

La investigación referida a los sucesos ocurridos entre el 9 de febrero de 1975 y 23 marzo de 1976 comenzó con una denuncia particular, por los hechos que perjudicaron a Néstor Juan Agustín Zurita y María Rosa Zurita, a partir de la cual el Ministerio Público Fiscal amplió progresivamente la investigación hasta que, en agosto de 2012, se solicitó la detención de los imputados. La megacausa Operativo Independencia fue la decimosegunda que se realizó en Tucumán por delitos de lesa humanidad, pero presentó dos características distintivas con respecto a los anteriores. ${ }^{1}$ En primer lugar, por primera vez fueron juzgados los crímenes efectuados por las fuerzas represivas en un período previo a marzo de 1976, en el marco de un gobierno constitucional -el de María Estela Martínez de Perón-, y en los que el despliegue de la V Brigada del Ejército significó la instalación de un aparato represivo que instauró el terrorismo de Estado a partir de febrero de $1975 .^{2}$ Este hecho no resultó menor, en tanto que cuestiona una línea historiográfica que estableció que la represión política y el terrorismo de Estado comenzaron el 24 de marzo de 1976. En este caso, la megacausa pone en el centro de la escena una memoria local y regional vinculada con la implementación de la violencia política, y rompe así con una memoria hegemónica porteño-céntrica que invisibilizó las perspectivas locales. En segundo lugar, si bien la megacausa centró su atención en lo sucedido en Tucumán, muchos de los testigos provenían de otras provincias, lo que demuestra que la implementación del terrorismo de Estado fue regional, ya que afectó a las provincias de Salta y Santiago del Estero. Asimismo, un porcentaje significativo de los afectados eran obreros azucareros, que fueron sometidos a la violencia de capataces y dueños del ingenio mucho antes de los setenta, hecho que da cuenta de memorias más largas de la represión (Catela Da Silva, 2007, p. 219).

El 5 de mayo de 2016 comenzaron las audiencias, que contaron con 20 imputados, 1400 testimonios ofrecidos, 15 querellas y 270 víctimas. El tribunal estuvo conformado por el Dr. Gabriel Casas, el Dr. Carlos Jiménez Montilla y el Dr. Carlos Reynaga, y un juez suplente. En esta escena judicial participaron los actores profesionalizados -al decir de Sarrabayrrouse (2011)-, quienes son los encargados de implementar justicia y de construir la verdad jurídica. El público que asistió al juicio le otorgó legitimidad a la escena judicial, motivo por el cual la convocatoria realizada por los organismos de DDHH fue constante.

El Ministerio Público Fiscal, a partir de la autorización del tribunal, planificó las inspecciones, con la finalidad de mostrar la zonificación y la estructura represiva que había implementado la V Brigada del Ejército al mando de Acdel Vilas. Por este motivo, resulta necesaria la descripción y caracterización del espacio donde se desarrolló el Operativo Independencia.

\section{El espacio territorial del Operativo Independencia y la instauración del aparato represivo}

Los juicios de lesa humanidad tienen la característica de ser extraordinarios (Schoenle, 2013, p. 15), por eso su definición de megacausa, debido a la cantidad de crímenes que se juzgan, el número de imputados; en ellos se reconstruyen hechos que afectaron a un sinnúmero de personas -entre víctimas testigos y desaparecidos- y que alteraron la vida de espacios enteros, como ocurrió en la primera parte de la implementación del Operativo Independencia (TOF, 2015, f. 281).

El 9 de febrero de 1975, mediante el decreto 261/75, el gobierno de María Estela Martínez de Perón autorizó el accionar represivo del Ejército en la provincia de Tucumán, hecho que inauguró una nueva forma de tratamiento de los detenidos, debido que 
hasta febrero de 1975 -de acuerdo con las leyes no 20642/74 y 20840/74, ambas de carácter claramente anticonstitucional- los "delitos subversivos" eran penados con la detención y puesta a disposición del Poder Ejecutivo Nacional (en adelante, PEN), y posteriormente a febrero de ese año, la modalidad represiva suma la condición de "clandestina", sustentada en el secuestro, la tortura, la violación y la desaparición u homicidio de personas sospechadas de "subversivas" (TOF, 2015, f. 282).

La catalogación por parte del Estado o de los militares como "subversivos" a los detenidos no comenzó en 1975, sino que fue producto de un proceso de construcción cuyo primer antecedente fue la dictadura de Onganía en 1966, a partir del cual se estructuró una situación de excepcionalidad que fue creciendo desde la década de los setenta; con la puesta en vigencia de una serie de leyes y decretos de defensa y seguridad interna en relación con la contrainsurgencia (Eidelman, 2008; Carassai, 2010; Pontoriero, 2012, 2014, 2015, 2017, 2018; D’Antonio y Eidelman, 2016). De acuerdo con Marina Franco, entre 1973 y 1976 se construyó el enemigo de la nación, escenario presente durante la ejecución del Operativo Independencia (Franco, 2012). Este contexto significó la implementación de diversos mecanismos de control de la población civil, la instauración del terror y la construcción del imaginario social de que el silencio era salud. En este sentido, el área de influencia de dicho operativo abarcó, en una primera etapa, los departamentos de Monteros, Famaillá y Lules, cuyas ciudades cabeceras se encuentran a la vera de la ruta nacional no 38 (Jemio y Pisani, 2012). En este espacio se instauró el "teatro de operaciones", al mando del comandante de la V Brigada de Infantería Acdel Vilas, con asiento en las provincias de Tucumán, Salta y Jujuy y que a su vez subordinó al personal de la Gendarmería, la Policía Federal y la Policía de Tucumán. Asimismo, el poder militar instrumentó un aparato propagandístico que legitimó el accionar de las operaciones militares en el sur tucumano (Garaño, 2015, p. 58).

Se establecieron áreas de influencia y de control en el trazado de la ruta nacional № 38 con la finalidad de cortar cualquier vínculo de la población civil con la Compañía de Monte Rosa Jiménez del Ejército Revolucionario del Pueblo (ERP). Este escenario propició el establecimiento de bases militares en ingenios como Lules, Nueva Baviera, Santa Lucía, Fronterita y San Pablo. En este espacio se implementaron diversas prácticas de disciplinamiento social y de acción cívica que, en el caso del Operativo, se orientaron a eliminar la amenaza "subversiva" que utilizaba el monte tucumano como su escenario de acción. En tal sentido, el objetivo de la intervención militar no tuvo como propósito el enfrentamiento con la compañía de Monte del ERP, sino debilitar los vínculos que existían entre ella y la población civil, mediante mecanismos como el aislamiento, la identificación y desaparición de una porción de la sociedad considerada afín a la ideología marxista.

Asimismo, el circuito de las "inspecciones oculares" realizado por el tribunal el 9 de marzo de 2017 tuvo como eje el departamento de Famaillá. En este lugar, se estableció un circuito represivo que tuvo diferentes características de acuerdo con el emplazamiento de los CCD. Por un lado, en el caso de los CCD de uso eventual como las bases y campamentos militares, al igual que la comisaría y la escuela Lavalle ubicados en el centro de la ciudad de Famaillá, estos espacios estaban destinados a la detención de pobladores de la zona como forma de disciplinamiento social. Por otro lado, la escuelita y los conventillos del Ingenio Fronterita fueron CCD permanentes (Jemio y Pisani, 2012). De la misma manera, el proceso represivo en este último comenzó en 1974, pero en el período que se analiza en este artículo, se registran siete víctimas que fueron detenidas allí, y un desaparecido (Centro de Estudios Legales y Sociales [CELS], 2016, p. 81).

Las inspecciones oculares sirvieron para el reconocimiento del espacio por parte de los testigos, de sus lugares de detención y la dinámica del circuito represivo. Esto les 
permitió el relato en primera persona de lo que había sucedió, pero también los despojó de toda "subjetividad", debido a que, antes de comenzar, los testigos juran decir la verdad y nada más que la verdad. En este sentido, como decíamos, a partir de las sentencias la justicia construyó una verdad jurídica acerca de lo sucedido durante el terrorismo de Estado y la violación sistemática a los derechos humanos que posteriormente produjo una verdad "histórica". En este de proceso de reconstrucción de los hechos, no solo participaron los actores judiciales, sino los testigos de concepto -académicos y periodistas, entre otros-, que aportaron su conocimiento acerca de lo acontecido. La justicia, en este sentido, con el paso del tiempo se nutrió de fallos de la Corte Interamericana de Derechos Humanos, que sentaron jurisprudencia y habilitaron la posibilidad de incorporar las inspecciones oculares como una forma de indagar de manera directa el lugar donde se emplazaban los CCD. En estos espacios, el interrogatorio comienza a partir de la lectura de los nombres de las personas que declaran y, posteriormente, cuál era su relación con ese espacio o cómo llegaron a él. Esto resulta fundamental, porque da cuenta del contexto de las víctimas, si eran trabajadores, empleados de ingenio, militantes políticos, etc., hecho que le brinda carnadura al testimonio.

\section{Las inspecciones oculares como visibilización de los CCD}

En 1998 se realizó la Conferencia Diplomática de Plenipotenciarios de las Naciones Unidas; en ella se aprobó el Estatuto Roma, que implementaba las inspecciones oculares en los procedimientos de los juicios de lesa humanidad. Al tratarse de acuerdos internacionales relacionados con la aplicación de una jurisprudencia que transforma a la ley en algo que está por encima de las leyes de los Estados, su incorporación generó una serie de modificaciones constitucionales o fallos de la Corte Suprema de Justicia - en el caso de Argentina- que generó reformas en el derecho penal. En nuestro país, en 2002 se presentó un proyecto de ley que fue rechazado y luego de una serie de modificaciones fue aprobado por la Cámara de Diputados de la Nación en 2006 (Laboría, 2010).

De acuerdo con el Código Penal, las inspecciones oculares son un reconocimiento del lugar, una observación minuciosa y detallada que se realiza de lo general a lo particular, en búsqueda de evidencias físicas o biológicas que permiten, luego de un análisis o estudio técnico científico, determinar si estas tienen correspondencia con el hecho investigado o no, y su posterior valor probatorio para esclarecer la responsabilidad penal de su/s autor/es (Esteller, 2011).

Sin embargo, la norma no se establece de manera taxativa en los juicios de lesa humanidad. En el caso del Operativo Independencia pasaron 41 años para que se juzgara a los responsables, por lo que el testimonio cobró un significado fundamental, debido a que la escuelita no fue intervenida por ningún equipo de arqueología forense hasta finalizado el juicio; en el caso del Fronterita, al tratarse de una fábrica en funcionamiento, su intervención resulta aún más difícil.

Un elemento a considerar antes de relatar las dos inspecciones se relaciona con el ritual jurídico, que sale de un escenario formal como la sala de audiencias del TOF, donde se producía la disputa de sentido (Feld, 2002 p. 43; Mira, 2011, p. 337), a un ámbito totalmente diferente, en donde se permitió permitió ciertas digresiones a los testigos. Asimismo, del tribunal solo participaron el presidente, el Dr. Casas y el Dr. Jiménez Montilla. Tampoco fueron todos los miembros de la defensa oficial y del Ministerio Público Fiscal; lo contrario sucedió con las querellas particulares que se constituyeron de acuerdo a los testigos involucrados en esos CCD. Asimismo, participaron los organismos de $\mathrm{DDHH}$, la prensa y actores no profesionales vinculados con el ámbito académico o con la militancia política, que ven estos espacios como instancias de acompañamiento del proceso. 
En el caso que aquí se investiga, el circuito de las inspecciones oculares incluyó previamente la visita al ingenio Santa Lucía, la Chimenea Mota de Caspinchango -donde se había emplazado una base militar- donde estuvieron algunos detenidos-desaparecidos antes de ser trasladados a la "escuelita" de Famaillá. Esta reconstrucción del circuito represivo generó una gran movilización de vehículos con miembros del tribunal, personal de Gendarmería - que realizaba el registro fílmico-, el Ministerio Público Fiscal junto con las querellas particulares, como así también la defensa oficial y las particulares, periodistas, miembros del grupo de acompañamiento, organismos de DDHH y cientistas sociales. Todos ellos brindaron el marco de legalidad al proceso judicial, en tanto fueron testigos de las preguntas del presidente del tribunal y acompañaron todo el recorrido. Esto resultó interesante porque los testigos construyen un sentido de la memoria que se expresa en un relato comunicable (Jelin, 2002) y ese pasado es reconstruido a partir de un diálogo e interacción con los actores judiciales.

\section{La escuela Diego de Rojas}

La Escuela Diego de Rojas o "escuelita de Famaillá" se ubica sobre la ruta interpueblo n 324 que une a la ciudad de Famaillá con el ingenio Fronterita y Santa Lucía, espacio en donde se instalaron bases militares (Mercado, 2003). En este CCD, de acuerdo con el Archivo Nacional de la Memoria, se privó de su libertad a aproximadamente 1000 personas entre 1975 y 1977. Luego dejó de funcionar para abrir sus puertas como escuela de nivel primario, secundario y posteriormente terciario. En 2011, frente al pedido de los organismos de DDHH, se gestionó el traslado de la comunidad educativa al nuevo edificio, a fin de transformar la escuelita en un sitio de memoria, cuestión que fue implementada en 2012 bajo el amparo de la ley $26.691 .^{3}$

Esta situación generó una lucha política por la memoria, entre los organismos de DDHH y su intención de recuperar el espacio como sitios de memoria, y la comunidad educativa - directivos, docentes y estudiantes -, que se resistieron al traslado. Esto enfrentó dos sentidos del pasado, uno marcado por el terrorismo de Estado, los crímenes de lesa humanidad y la idea de Memoria, Verdad y Justicia; y otro vinculado con una postura negacionista de ese pasado -que se mantiene hasta la actualidad en algunas partes del sistema educativo- que sostiene la teoría de los dos demonios. Estos campos en disputa se vincularon con la necesidad de legitimar su "verdad" y, en él, los docentes como agentes estatales jugaron un rol fundamental al sostener la idea de que ese espacio siempre había sido una escuela, con lo cual invisibilizaban el hecho de que fue un CCD. ${ }^{3}$

Alrededor de las 12.30 de la jornada señalada para la inspección se constituyó el tribunal junto al Ministerio Público Fiscal, querellas particulares y la defensa pública y las defensas particulares. En esta ocasión participaron algunos testigos que relataron su vivencia durante su cautiverio en el CCD. Se recorrieron las distintas aulas a fin de que los testigos identificaran en cuál de ellas había estado. Esto generó intervenciones de las defensas particulares, que argumentaron que, en la etapa de instrucción y en la sala del juicio, los testigos habían declarado que estuvieron vendados todo el tiempo, motivo por el cual su declaración era contradictoria, cuestión que fue rebatida por el Ministerio Público Fiscal.

Los pedidos de ambas partes hacia el juez representaron disputas por el poder en el escenario jurídico. El magistrado, en estas ocasiones, a diferencia de lo que ocurre en la sala -donde se posiciona en el sistema adversarial como un árbitro entre las partes- era él quien definía o no la continuidad de los testimonios o rechazaba los pedidos de las defensas. El presidente del tribunal permitió que los testigos se explayaran aduciendo que el testimonio en la sala era lo importante. Era él quien direccionaba las preguntas -en la sala del tribunal son las partes las que interrogan- y era el testigo durante la inspección quien relataba su verdad. "Una verdad probablemente construida a partir
3. La teoría de los dos demonios en Argentina, es una visión según la cual los actos de violencia y de Terrorismo de Estado implementado por las fuerzas de armadas y de seguridad, son equiparables con los actos de violencia cometidos por las organizaciones político armadas como Montones y Ejército Revolucionario del Pueblo (ERP). En este contexto, los crímenes de Lesa Humanidad cometidos por las fuerzas armadas fueron un exceso en el marco de una guerra civil. 
4. Por este motivo, el momento de testificar tiene que estar exento de urgencias e interrupciones pues la persona víctima testigo de un delito sexual reúne en torno a sí misma dos características: por un lado, al brindar testimonio hace referencia a un hecho pasado y por otro lado, revive, reactualiza y reedita experiencias altamente dolorosas. Al respecto, veáse Lesa Humanidad: dictan un protocolo sobre la declaración de víctimas de delitos sexuales, en http://www.cij. gov.ar/nota-10713-Lesa-humanidad-dictan-un-protocolo-sobre-ladeclaraci-n-de-v-ctimas-de-delitossexuales.html de una experiencia arrasadora y se considera que ese arrasamiento dejo huellas en su testimonio" (Wikinski, 2016, p. 96). Es decir que ese trauma se reactualiza de acuerdo con el tenor de la experiencia traumática vivida, lo que provoca silencios, llantos o la necesidad de contar lo sucedido. A medida que se realizaba la "inspección ocular", los testigos relataron los recuerdos que tenían del momento de su detención en la "escuelita". En una primera instancia, no reconocieron la entrada que se utiliza actualmente para ingresar al sitio de memoria, porque había sido modificada cuando empezó a funcionar como escuela. Asimismo, los testigos recordaron que al momento de su detención habían sido trasladados allí en un Unimog, otros en auto, por lo cual pensaban que habían ingresado por la parte trasera del predio. Los testigos reconocieron espacialmente dónde se situaban los baños y la cocina del CCD. En frente de esta, Fermín Núñez relató que se encontraba la oficina donde había declarado y donde le entregaron sus pertenencias cuando lo pusieron en libertad. Fue este último el que marcó una diferencia entre el piso de la galería de la "escuelita" respecto del piso de la cancha de básquet que se construyó posteriormente. De acuerdo con Núñez, existía un desnivel entre el piso de la galería y el césped. Esto generó interrogantes por parte de la defensa pública, que repreguntó cómo él sabía eso, a lo que Núñez respondió que lo habían tenido un rato sin la venda en los ojos, e incluso que una persona la fotografió. Estos relatos buscaron ser desestimados por la defensa, pero para el Ministerio Público eran de vital importancia porque se trataba de testimonios en primera persona.

Uno de los "testigos oculares" era una mujer (RC), quien sufrió una crisis nerviosa en una de las últimas aulas que se visitaron. Esto promovió la intervención del grupo de acompañamiento a testigos y de su hija, quien había asistido con ella a la inspección. La angustia de RC provocó que el juez le preguntara si quería continuar con el grupo, a lo que la testigo contestó que el motivo de su estado de ánimo se vinculaba con el recuerdo de las repetidas veces en que había sido abusada en esa aula por parte de un soldado. En el caso de RC, un espacio en particular de la escuelita reactualizó el trauma desde lo emocional y lo afectivo por lo que había afrontado en esa aula, no solo vinculado con los abusos sexuales, sino también con la violencia de género y la deshumanización de su persona.

Esta situación resultó incómoda para el juez, quien no repreguntó acerca de esos sucesos, sino que interrogó a otros testigos acerca de esa aula. Esto se debió a que en la elevación a juicio de la megacausa Operativo Independencia se contemplaron los delitos sexuales como parte de la acusación del Ministerio Público Fiscal, pero esta clase de declaraciones requieren de un protocolo especial, motivo por el cual solo se mencionan las letras iniciales del nombre y apellido de la testigo.

En el caso de Tucumán, el TOF saco una acordada n 04/13 dictada en la causa "Arsenal Miguel de Azcuénaga y Jefatura de Policía de Tucumán s/secuestros y desapariciones", mediante la cual, a partir de instrumentos internacionales y doctrina especializada, se reconoce que las personas presuntamente víctimas de delitos sexuales presentan una situación extremadamente delicada al momento de brindar testimonio. ${ }^{4}$

Otra cuestión significativa se relacionó con los testimonios individuales, que en algunos casos se transformaban en una memoria colectiva, como ocurrió con la sala de torturas. Es decir que ese pasado fue reactualizado en el presente a partir de un propósito (Jelin, 2002, p. 18), que es el sentido de justicia en torno al juicio del operativo y a la posterior condena como elemento legitimador de las denuncias de los organismos de DDHH. Del mismo modo, si bien existe una memoria colectiva de lo que representó como CCD "la escuelita", las vivencias individuales son totalmente contrapuestas según se tratara de un militante político o de una persona bajo sospecha de comportamiento subversivo; aunque los elementos comunes entre todos eran la deshumanización del cuerpo, la inmovilidad, la oscuridad y las condiciones de detención (Calveiro, 2004, p. 28). De todas formas, los 
testigos recuerdan que, a pesar de no poder ver y de que se les impedía hablar entre ellos, algunos reconocieron las voces de familiares y amigos, relato esencial al momento de identificar el circuito de detención que atravesaron las víctimas hasta hoy desaparecidas.

Estas memorias que se visibilizan en los CCD son diferentes a las que aparecieron en la sala del tribunal, debido a que los testigos se sitúan en el mismo espacio en donde sufrieron en carne propia la experiencia del terrorismo de Estado, hecho que en muchos casos revive ese pasado traumático y provoca una revictimización ante las preguntas del juez o de la defensa. Sin embargo, en esta ocasión el juez no permitió preguntas que revictimizaran a los "testigos oculares", sino que dejó que relataran sus recuerdos, lo que provocó que en diversos momentos aquellos se quebraran emocionalmente.

\section{El ingenio Fronterita}

El ingenio se ubica cerca de la ruta interpueblo ${ }^{\circ} 324$ que une Famaillá y Santa Lucía. ${ }^{5}$ En 1975, la fábrica azucarera era administrada por Camilo Bergero, mientras que José Antonio Minetti revestía el carácter de representante legal como presidente del directorio de José Minetti y Cía. Ltda. SA, titular de dicho ingenio (CELS, 2016, p. 81). El proceso represivo se inició en octubre de 1974 hasta septiembre de 1976, hecho que conllevó, durante el Operativo Independencia, que se instalara una base en la propiedad del ingenio (TOF, 2015, p. 270).

Un dato significativo de esta empresa fue la continuidad en sus actividades productivas durante el Operativo y posteriormente durante la dictadura cívico-militar, lo que generó un aumento de su producción y de su injerencia en la zona. Asimismo, el área de influencia de la base del ingenio se extendía hacia otros parajes, como Monte Grande, Tres Almacenes, La Rinconada, San José de Buena Vista, Sauce Huacho y Finca Triviño, donde fue registrado un número considerable de víctimas (CELS, 2016, p. 93).

La represión durante el Operativo tuvo la finalidad de disciplinar al sindicato que tenía representación en el ingenio y a los referentes sindicales de la zona. En este sentido, un elemento clave para comprender esta postura por parte de los militares se vinculó con la alta conflictividad de los sindicatos, que -a partir del retorno de Perón en 1973buscaron la reapertura de los ingenios cerrados en 1966. Del mismo modo, la identificación del fenómeno guerrillero con la pobreza persiguió el propósito de considerar a Tucumán como un hervidero de "subversivos", y la identificación de la "subversión" no solo con los guerrilleros urbanos y rurales, sino también y específicamente, con todo cuestionamiento político y social, acciones de protesta o lucha política o sindical en las fábricas, universidades y escuelas (TOF, 2015, p. 280).

La inspección ocular comenzó a las 15.00 en la entrada principal del ingenio. Allí, el juez preguntó dónde habían estado los militares, y los tres testigos coincidieron en que el aspecto actual no era igual al de 1975. Antes de comenzar la declaración, se tomó lectura del nombre de los testigos, y el juez comenzó la inspección diciendo que se iba a realizar un reconocimiento del ingenio Fronterita donde había funcionado un CCD, pero rápidamente se rectificó al darse cuenta del error cometido y se refirió a que se iba a observar dónde estaba la base militar. Esta rectificación del juez con respecto a sus dichos se vincula con la necesidad de mantener el ritual jurídico -es decir, la imparcialidad ante los hechos- durante la inspección. Los tres "testigos oculares" se identificaron como obreros del ingenio, motivo por el cual conocían la estructura edilicia, pues desde su infancia vivieron en colonias obreras del Fronterita o en la ciudad de Famaillá. Coincidieron en que la calle principal no era la actual, porque en ese lugar había una comisaria de la policía provincial y la zona se encontraba llena de militares.
5. Con mi familia, en vacaciones de verano, recorríamos dos o tres veces al año la ruta interpueblo $n^{\circ}$ 323. Este paisaje azucarero cambió sustancialmente de significado a partir de la inspección ocular, al exotizar lo cotidiano (DaMatta, 1978) y comprender cómo los ingenios fueron utilizados como bases militares e integraron el circuito represivo durante el Operativo Independencia. 
A unos 400 metros de la comisaría, se estableció la base militar. En la entrada de la base, los militares se pertrecharon y establecieron un control, en donde se instaló una barrera, había bolsas con arena, en donde bajaban a la gente que iba en el colectivo el "Centauro" hasta la colonia seis, y los registraba. (Declaración de Enrique Antonio Amaya)

A partir de las primeras declaraciones, el juez rodeó junto a los testigos el ingenio por un camino adyacente, hasta llegar a un espacio fuera de los límites actuales del Fronterita, donde se observaba una serie de casas abandonadas. Uno de los testigos (Mercado) relataba lo siguiente:

Ahí había un control de los militares, ya le voy a hacer mostrar, porque yo me he retirado recién el año pasado de acá, yo he trabajado 46 años en la empresa y he nacido aquí en la colonia y yo conozco bien -esboza una sonrisa-; yo me acuerdo que nos han traído, mire cómo nos han traído vendados vendado, no sé si fue esta u otra pared donde nos tuvieron parados parado.

Esas casas, de acuerdo con los testigos, servían de alojamiento de los trabajadores transitorios del ingenio que venían para la zafra desde los valles (Amaicha, Tafí del Valle, Santamaría) y desde provincias vecinas, como Santiago del Estero. El juez ingresó a ese espacio con los testigos, y Mercado aludió que lo habían traído de la Colonia III, que dista a $3 \mathrm{~km}$ del Fronterita, lo vendaron y lo ubicaron en una casa; a él y a otras personas.

En la habitación nos preguntaron los nombres y los números de documento [...] nos han tenido hasta más o menos las 11 de la mañana y me llevaron a Famaillá... en el caso mío (relata Mercado...) y a mí me torturaron acá (Amaya) y a mí también (Vázquez) pero después me llevaron a Famaillá.

Asimismo, los militares movieron la base hacia la laguna o, como le dicen en el lugar, el Tambo, de acuerdo con lo que relatan los "testigos oculares", quienes no precisaron exactamente en qué día de mayo de 1975 tal cosa había ocurrido. Eso sucedió cuando llegaron los trabajadores golondrinas a la zafra. En el "Tambo" había carpas y casas prefabricadas donadas por el ingenio para que desocuparan el predio de las viviendas de material. También se habían construido dos galpones: "uno lo desaparecieron, que eran donde torturaban gente" comentó el testigo Mercado. Uno de los testigos oculares relató que él se había ido a vivir a Famaillá en el año 1979, y que en ese momento los militares permanecían en el ingenio.

El juez volvió a preguntar acerca de los galpones, y Vázquez declaró que eran de material, con un sistema de techado de tipo cumbrera en donde los ataban de los pies y ponían tachos con agua abajo para torturarlos e interrogarlos. Mercado relató que el predio se limpió pero que, con el cambio de dueño de la empresa, la parte en donde se encontraban había quedado abandonada. Al llegar al lugar donde están los galpones, Vázquez y Mercado ubicaron su emplazamiento, y destacaron que uno de ellos se mantiene en pie, mientras que el que se usaba para torturar a la gente fue demolido. El juez le pregunto a Vázquez cuántas veces lo habían secuestrado, y él afirmó que fueron siete veces, las últimas, junto con su padre y madre, que también fueron detenidos. Resultó interesante esta última parte de la declaración, porque da cuenta de una naturalización de la violencia y la represión. Es decir que es una memoria dentro un marco social determinado -el obrero azucarero y el ingenio-, y los recuerdos de los tres testigos tienen que ver con ese marco social compartido y con la clase social a la que pertenecían. Por este motivo, la naturalización de la violencia es inconsciente y aflora a partir del testimonio brindado. 
Tras una serie de preguntas del Ministerio Público Fiscal acerca de quién era dueño actualmente del predio en donde se realizaba la inspección ocular, los tres testigos afirmaron que era de Minetti, menos el ingenio, que fue vendido a la empresa Coca Cola.

Ante la falta de nuevas preguntas por parte de los actores profesionales, el juez dio por finalizadas las "inspecciones oculares", con lo cual, las personas que habían participado de ellas se dirigieron a sus autos para retornar a la ciudad.

\section{Conclusiones}

En el caso de Tucumán, la violencia política se incrementó desde el cierre de once ingenios durante la dictadura de Juan Carlos Onganía, en 1966. Este proceso sumió a la población en la pobreza y acrecentó la protesta social; este contexto socioeconómico fue un campo propicio para el accionar del Partido Revolucionario de los Trabajadores -Ejército Revolucionario del Pueblo (PRT-ERP) y de Montoneros. Esto promovió en 1975 la instauración del aparato represivo durante el Operativo Independencia, a partir de la aprobación del decreto $261 / 75$, hecho que suscitó la criminalización de la protesta social, la lucha contra los "subversivos" y el disciplinamiento social.

Una cuestión central de este artículo fue la idea de romper con una memoria hegemónica que asumió que el terrorismo de Estado en la Argentina había comenzado el 24 de marzo de 1976. Este visión desde una postura porteño-céntrica invisibilizó las diferentes escalas temporales de análisis y la forma en que se implementó la represión en el resto del país. Pero las denuncias de los organismos de DDHH de Tucumán ante la justicia federal y la elevación a juicio de la megacausa Operativo Independencia contribuyó a visibilizar las memorias subterráneas - al decir de Catela Da Silva (2014) - a partir de los testimonios vertidos en el juicio.

En este escenario jurídico se produjeron disputas por el poder entre los actores profesionales, tanto el Ministerio Público Fiscal y las querellas particulares frente a la defensa pública y las defensas particulares, que fueron más notorias cuando se realizó la "inspección ocular" en la "escuelita". En este sentido, se conjetura que el juez se tomó una serie de licencias con respecto a las declaraciones de los "testigos oculares", quienes relataron donde habían sido ubicados durante su detención en este CCD. Ante las quejas por parte de la defensa, el juez objetó todos los argumentos. Se piensa que este accionar del juez estaba vinculado con la dimensión jurídica de un juicio que se llevaba a cabo 41 años después de sucedidos los hechos; esto sumado a la dimensión simbólica de la "escuelita", que fuera el primer CCD de permanencia y exterminio previo al golpe militar de 1976.

De la misma manera, los escenarios de las inspecciones oculares son totalmente diferentes. Por un lado, la "escuelita" es un espacio paradigmático. El CCD se instaló en la estructura de una escuela en construcción que, luego de 1979, se transformó en un establecimiento educativo. A partir de las demandas de los organismos de DDHH, en 2011 se consiguió el traslado de la escuela a un nuevo edificio. Este proceso se realizó en el marco de una gran resistencia por parte de los educadores del establecimiento, quienes reproducían la teoría de los dos demonios. Es decir, que la "escuelita" significó un escenario de disputa acerca de una memoria hegemónica impuesta por las Fuerzas Armadas acerca de la guerra contra la "subversión", que continuó siendo reproducida en el ámbito educativo, hecho que invisibilizó al predio como CCD. La apertura del sitio de memoria no solo interpeló al sistema educativo sino a los vecinos de Famaillá, quienes por el cambio generacional desconocían que a pocas cuadras del centro de la ciudad había funcionado un CCD durante el Operativo Independencia. 
Por otro lado, el ingenio Fronterita continúa actualmente en actividad, aunque la parte en donde se ubicaba la base militar que se utilizó como CCD transitorio fue abandonada. Sin embargo, este espacio no fue intervenido hasta que la justicia realizó la inspección ocular, lo que permitió que algunos pobladores de las colonias obreras que trabajaban en el ingenio declararan en el marco de la megacausa, y esa memoria fue traída al presente como parte de la verdad jurídica que se vislumbró en la sentencia que elaboró el tribunal. Esta reconoció que durante el Operativo Independencia se había implementado el terrorismo de Estado y que se cometieron crímenes de lesa humanidad.

En esta línea de análisis, un elemento que subyace a partir de los testigos oculares del ingenio Fronterita fue el fuerte vínculo entre los obreros y la fábrica azucarera. En el caso de Mercado, a pesar de sufrir torturas en el predio de la empresa, volvió a desempeñar tareas como obrero del ingenio. Con respecto a Vázquez, su relato da cuenta de cómo el Ejército se ensañaba con ciertas personas y las "visitaba" de manera recurrente o las detenía como una forma de disciplinamiento social, pero además, de una naturalización de la violencia que se había ejercido hacia él. Asimismo, en ambos casos, los relatos visibilizan el paradigma de la industria azucarera como motorizadora de ingresos para los sectores obreros, quienes no tuvieron la posibilidad de reinsertarse en otra actividad productiva.

De la misma manera, las inspecciones oculares interpelaron la memoria de los testigos, quienes en algunos casos reactualizaron el trauma de la tortura y en otros permitió la posibilidad de contar su paso por el CCD. Por este motivo, se piensa que estas inspecciones oculares son fundamentales para la ubicación geográfica espacial de los hechos, a fin de que la verdad jurídica en disputa en las audiencias se transforme en una "verdad histórica", la cual tomó cuerpo en la sentencia de la megacausa.

De la misma manera, el ritual jurídico cambió en las inspecciones oculares, porque la interacción era directa entre el juez y los testigos. Esta cercanía humaniza en cierta forma la figura del tribunal, que, si bien mantuvo el control de la escena judicial, permitió ciertas digresiones que no son comunes en la sala. Sin embargo, a pesar de que los miembros del tribunal están más relajados, siguen actuando como mediadores entre las partes, pero sobre todo en la inspección ocular en la "escuelita" de Famaillá, el presidente del jurado evitó la revictimización de los testigos.

Asimismo, resultó notorio que, a pesar de toda la política de memoria llevada a cabo en el ámbito nacional desde 2003, durante el gobierno de Cambiemos se produjo una reactualización de la teoría de los dos demonios, hecho que politizó el escenario del juicio y que desembocó en fallos que presentaron numerosas absoluciones.

\section{Financiamiento:}

Este documento es resultado del financiamiento otorgado por el Estado Nacional, por lo tanto queda sujeto al cumplimiento de la Ley № 26.899 . CONICET. Tema de investigación como investigador adjunto.

\section{Biografía}

Doctor en Ciencias Sociales (Orientación Historia) de la Universidad Nacional de Tucumán. Investigador adjunto del CONICET. Miembro fundador de la Asociación Argentina de Investigadores en Historia. 


\section{Q Referencias bibliográficas}

》 Allier Montaño, E. y Crenzel. E. (Coords.) (2015). Las luchas por la memoria en América Latina. Historia reciente y violencia política. México: Bonilla Artigas.

"Borón, A. (2003). Estado, capitalismo y democracia en América Latina. Buenos Aires: Consejo Latinoamericano de Ciencias Sociales (CLACSO).

"Calveiro, P. (2004). Poder y desaparición: los campos de concentración en Argentina. Buenos Aires: Colihue.

»Calveiro, P. (2005). Política y/o violencia. Una aproximación a la guerrilla de los años 70. Buenos Aires: Norma.

"Carassai, S. (2010). Antes de que anochezca. Derechos Humanos y clases medias en Argentina antes y en los inicios del golpe de Estado de 1976. América Latina Hoy, 54, 6996. doi: 10.5585/prismaj.v8n2.1701

»Carnovale, V. (2007). Aportes y problemas de los testimonios en la reconstrucción del pasado reciente en la Argentina. En M. Franco y F. Levín (Comps.). Historia reciente. Perspectivas y desafíos para un campo en construcción (pp. 155-181). Buenos Aires: Paidós.

"Catela Da Silva, L. (2001). No habrá flores en la tumba del pasado. La experiencia de reconstrucción del mundo de familiares de desaparecidos. La Plata: Ediciones Al Margen.

»Catela Da Silva, L. (2007). Poder local y violencia: memorias de la represión en el noroeste argentino. En A. Islas (Comp.). En los márgenes de la ley. Inseguridad y violencia en el cono sur. (pp. 211-227). Buenos Aires: Paídos.

"Catela Da Silva, L. (2014). “Lo que merece ser recordado...”. Conflicto y tensiones en torno a los proyectos públicos sobre los usos del pasado en los sitios de memoria. Clepsidra. Revista Interdisciplinaria de Estudios sobre Memoria, 2, 28-45.

»Centro de Estudios Legales y Sociales (CELS) (2016). Responsabilidad empresarial en delitos de lesa humanidad. Represión a trabajadores durante el Terrorismo de Estado. Buenos Aires: Facultad Latinoamericana de Ciencias Sociales (FLACSO).

"Chama, M. y Sorgentini, H. (2010). A propósito de la memoria del pasado reciente argentino: Notas sobre algunas tensiones en la conformación de un campo de estudios. Aletheia, 1, 2-8. Recuperado de http://www.memoria.fahce.unlp.edu.ar/art_revistas/ pr.4267/pr.4267.pdf

" Cortés Navarro, G. (2015). La masacre de la calle Azcuénaga. Tucumán, 1976. Historia, voces y memoria, 8, 111-123. Recuperado de https://doi.org/10.34096/hvm.n8.1666

»Damatta, R. (1978) Carnavales, malandros y héroes. Brasil: Fondo de Cultura Económica.

»D’Antonio, D. y Eidelman, S. (2016). El fuero antisubversivo y los consejos de guerra a los civiles en la Argentina de los años 70. Estudios Interdisciplinarios de América Latina y el Caribe, 27(2), 77-97. Recuperado de: http://eial.tau.ac.il/index.php/eial/article/view/1438

"Eidelman, A. (2008). La Cámara Federal en lo Penal. La actividad del fuero antisubversivo entre los años 1971-1973. En V Jornadas de Sociología. Universidad Nacional de la Plata, La Plata, Argentina.

》Esteller, G. (2011). La inspección ocular y su relación con el proceso penal. Revista Skopein, 4, 6-11.

»Feld, C. (2002). Del estrado a la pantalla: las imágenes del juicio a los ex comandantes en Argentina. Madrid: Siglo XXI. 
»Feld, C. (2009). Aquellos ojos que contemplaron el límite: La puesta en escena televisiva de testimonios sobre la desaparición. C. Feld y J. Stites Mor. (edas.) El pasado que miramos. Memoria e imagen ante la historia reciente (pp. 77-109). Buenos Aires: Paidos.

» Feld, C. (2016). Trayectorias y desafíos de los estudios sobre memoria en Argentina. Cuadernos del IDES, 32, 1-21.

» Franco, M. (2012). Un enemigo para la Nación. Orden interno, violencia y “subversión”, 19731976. Buenos Aires: Fondo de Cultura Económica.

" Garaño, S. (2015). Represión política, terror y rumores en el "teatro de operaciones" del Operativo Independencia (Tucumán, 1975-1977). Clepsidra, 3, 46-71.

"González Leegstra, C. (2012). "No le vamos a dar voz a los represores": (des) autorizaciones y (des) legitimaciones en las audiencias del juicio a Etchecolatz. Sociohistórica. Cuadernos del $\mathrm{CISH}, 29,87-105$.

» Halbwachs, M. (1968). La mémoire collective. París: Presses Universitaires de France.

» Izaguirre, I (1998). La política de la memoria y memorias de la política en Argentina. Razón y Revolución, 4, 1-19.

» Jelin, E. (2002). Los trabajos de la memoria. Madrid: Siglo XXI.

» Jelin, E. (2005). Los Derechos Humanos y la Memoria de la Violencia Política y la Represión: la Construcción de un Campo Nuevo en las Ciencias Sociales. Estudios Sociales, 27(1), 91-113. doi: http://dx.doi.org/10.14409/es.v27i1.2538

» Jelin, E. y Longoni, A. (Comps.) (2005). Escrituras, imágenes y escenarios ante la represión. Madrid: Siglo XXI.

» Jemio, A. y Pisani, A. (2012). Las explicaciones sobre el proceso genocida en los discursos de los pobladores de Famaillá, Tucumán. 1975-1983. Historia, voces recobradas y memoria. Revista del Programa de Historia Oral, 4, 135-168.

»Kahan, E. (2004). Recuerdos que mienten un poco. Vida y memoria de la experiencia judía durante la última dictadura militar. Buenos Aires: Prometeo.

»Kauffman, E. (1991) El ritual jurídico en el juicio a los ex comandantes. Buenos Aires: Mimeo.

» Kotler, R. (2006) Los movimientos sociales: Formas de resistencia a la dictadura. Madres de detenidos desaparecidos de Tucumán. Cuadernos de Historia Oral, 7, 1-44.

» Kotler, R. (2007). El Tucumanazo, los Tucumanazos 1969-1972. Memorias enfrentadas: entre lo colectivo y lo individual. En XI Jornadas Interescuelas/Departamentos de Historia. Universidad Nacional de Tucumán, San Miguel de Tucumán, Argentina.

» Kotler, R. (2008). Análisis del Informe de la Comisión Bicameral Investigadora de las Violaciones de los DDHH en la Provincia de Tucumán (1974 -1983). Prohistoria, 11, 29-48.

» Laboría, A (2010). Implementación en la Argentina del Estatuto Roma de la Corte Penal Internacional. Lecciones y ensayos, 88, 43-81.

» López, M., Figueroa C. y Rajland, B. (Eds.) (2010). Temas y procesos de la Historia Reciente de América Latina. Chile: Arcis.

» Mena, M. (2016). Los quiebres en el recuerdo: entre memoria y dictadura en la Argentina. Amerika, 15, 1-33.

» Mercado, L (2003). El ingenio Santa Lucía de Tucumán. Los primeros habitantes. Tucumán: Umbilicus Mundi 
» Mira, J. (2011). El juicio penal como puesta en escena. Una mirada etnográfica de los juicios por crímenes de lesa humanidad en la Argentina. Revista Electrónica del Instituto de Investigaciones “Ambrosio L. Gioja”, 5, 335-347. Recuperado de http://www.derecho.uba. ar/revistagioja/index_old. php?ided=6

» Nassif, S. (2011). Conflictos sociales protagonizados por obreros y estudiantes en Tucumán durante 1970. Conflicto Social, 4, 175-200. Recuperado de https://publicaciones. sociales.uba.ar/index.php/CS/article/view/376

» Nassif, S. (2012). Conflictividad social en la provincia de Tucumán durante la "Revolución Argentina”. El "Quintazo” o "Segundo Tucumanazo” de 1972. Revista Páginas, 7, 73-104. doi: http://dx.doi.org/10.35305/rp.v4i7.83

» Nassif, S. (2015). Protagonistas olvidados: las luchas obreras en Tucumán en los años '60 y principios de los '70. Estudios. Revistas del Centro de Estudios Avanzados, 34, 159-176. Recuperado de https://revistas.psi.unc.edu.ar/index.php/restudios/article/ view/13340/13541

» Ollier, M. (2005). Golpe o Revolución. La violencia legitimada, Argentina 1966/1973. Buenos Aires: Editorial de la Universidad Nacional de Tres de Febrero.

»Pontoriero, E. (2012). Pensamiento militar y legislación en defensa: la caracterización de la amenaza a la seguridad interna. ¿Continuidad o ruptura? (1963-1970). Contemporánea. Historia y problemas del siglo XX, 3, 149-165. Recuperado de http://www.geipar.udelar.edu. uy/wp-content/uploads/2014/10/Contemporanea03_2012-11-23-webO-o8.pdf

»Pontoriero, E. (2014). El tratamiento de los prisioneros de "guerra subversiva" en los reglamentos de contrainsurgencia del Ejército argentino (1955-1976). Revista Izquierdas, 19, 131142. Recuperado de https://biblat.unam.mx/hevila/lzquierdasSantiago/2014/no19/8.pdf

»Pontoriero, E. (2015). Estado de excepción y contrainsurgencia: El plan CONINTES y la militarización de la seguridad interna en la Argentina (1958-1962). Contenciosa, 4, 1-16. doi: http://dx.doi.org/10.14409/contenciosa.voi4.5080

»Pontoriero, E. (2017). Excepcionalidad jurídica y contrainsurgencia: claves para pensar la racionalidad militar en los inicios del terror de Estado en Argentina (1973-1976). Revista Páginas, 19, 53-74. Recuperado de https://revistapaginas.unr.edu.ar/index.php/RevPaginas/article/view/250

»Pontoriero, E. (2018). La seguridad interna como campo de batalla de la "guerra revolucionaria": contrainsurgencia y defensa nacional en los ámbitos político y militar de la Argentina (1963-1970). Boletín del Instituto de Historia Argentina y Americana "Dr. Emilio Ravignani”, 48, 84-120. Recuperado de http://ppct.caicyt.gov.ar/index.php/ravignani/article/view/12073

»Pucci, R. (2009). Tucumán 1975. La guerrilla y el terrorismo de Estado antes del golpe militar. Autoritarismo y dictadura en Tucumán. Estudios sobre cultura, política y educación. Buenos Aires: Catálogos.

»Salvi, V. (2012). De vencedores a víctimas: memorias militares sobre el pasado reciente en la Argentina. Buenos Aires: Biblos

»Sanjurjo, L. (2016). Las luchas por la memoria en la escena judicial. Una mirada etnográfica sobre los juicios de lesa humanidad. Cuadernos de Antropología Social, 43, 161-177. doi: https://doi.org/10.34096/cas.i43.2995

»Sarrabayrouse Oliveira, M. J. (1998). Poder Judicial. Transición del escriturismo a la oralidad, (Tesis de Licenciatura en Ciencias Antropológicas). Facultad de Filosofía y Letras, Universidad de Buenos Aires, Buenos Aires.

»Sarrabayrouse Oliveira, M. J. (2012). Poder Judicial y dictadura. El caso de la morgue. Buenos Aires: Reeves. 
"Schoenle, L. (2013). Juicios, memoria y políticas: posicionamientos y disputas por el sentido. Caso mega causa ESMA. En VII Jornadas Santiago Wallace de Investigación en Antropología Social. Facultad de Filosofía y Letras, Universidad de Buenos Aires, Buenos Aires, Argentina.

» Schoenle, L. (2015). Megajuicios. Extraordinariedad y desborde ritual judicial por delitos de lesa humanidad. Clepsidra. Revista Interdisciplinaria de Estudios sobre Memoria, 4, 134155. Recuperado de http://ppct.caicyt.gov.ar/index.php/clepsidra/article/view/Schoenle

» Tello, M. (2015). “Yo acuso”: un análisis antropológico sobre lo jurídico en los primeros testimonios acerca de la Perla. Clepsidra. Revista Interdisciplinaria de Estudios sobre Memoria, 4, 90-116. Recuperado de http://ppct.caicyt.gov.ar/index.php/clepsidra/issue/ view/Clepsidra.\%2oRevista\%2olnterdisciplinaria\%20de\%20Estudios\%20sobre\%20 Memoria.\%2oOctubre\%2O2015.\%20A\%C3\%B10\%2O2\%2C\%2oN\%C3\%BAmero\%204/ showToc

»Vitar, J. (2015). La construcción de otras memorias: Familiares de desaparecidos de Tucumán y el primer juicio a Bussi. Telar, 13-14, 299-320.

»Wikinski, M. (2016). El trabajo del testigo. Buenos Aires: La Cebra.

\section{Fuentes}

» TOF (2015), Exp. Autos de Procesamiento por Operativo Independencia, F.1-240.

» TOF, Registro fílmico, Secretaría de Derechos Humanos. Material cedido con autorización del Secretario. 